\title{
Consideration of Shape Characteristics for Apartments Incorporating Daylight and Energy Performance
}

\author{
Ji-Eun Lee and Kang Up Lee \\ Department of Architecture, University of Hanyang, Seoul 133-791, South Korea
}

\begin{abstract}
The objective of this paper is to design units with well-lighted environment and low-energy consumption in the apartment building. Their daylight and energy performance can be determined by the building shape and orientation. The paper initially produced the results of illuminations and energy efficiency using the daylight and thermal simulations by Autodesk "ECOTECT". It then provided the comparison on simulation results of two type buildings: Flat-type and L-type apartment. The available options for the design incorporating the environmental performance have less flexibility in flat-type apartments than in L-type ones. The best unit in the flat apartment is fixed from -45 to 45 degrees rotation, however, that in the L-type one can change depending on rotating the building. Moreover, if the upper level units had the appropriate environment, the lower level could have larger window areas in order to meet those daylight performance needs. Results show that the facade design should have the different window areas depending on the location of each unit. It can assist in the comfort and low-energy consumption design by using simulation tools that achieve the more predictable understandings.
\end{abstract}

Key words: Daylight performance, energy efficiency, passive housing, environmental simulation, building shape.

\section{Introduction}

\subsection{Research Background and Purpose}

The structure of a passive house is achieved by optimizing location, placement and shape of the building plans. For instance, the use of solar energy is applied in the best way to heat and light the indoor space without mechanical or electrical supply. In contrast, houses with a renewable energy system take advantage of solar energy to store the energy and transform it into other forms for producing electricity, heat for spaces and hot water. The system is required that actively absorbs natural energy and minimizes the loss of energy. This effect is associated with the efficiency of the mechanical systems rather than architectural design. Therefore, optimizing the utilization of solar energy is the most important to improve energy conservation.

Corresponding author: Ji-Eun Lee, Ph.D. candidate, associate research fellow, research fields: architectural design incorporating environmental performance, design standards for the apartment renovation and residential environment improvement. E-mail: jee@lh.or.kr.
The residential building with pleasant environment and low energy consumption is designed considering the correlation between form and energy use. For instance, the sunlight brought into inside plays a crucial role in making occupants feel comfortable as well as decreases the energy consumption. This concept is related to the government's demonstrating business for energy conservation, and Seoul is the first region in South Korea applying the energy management systems. Thus the amount of energy consumption will be considered as criteria for judging the value of the building just like fuel consumption efficiency of the car. Second, "energy consumption regulations for total amount" [1] has been in practice after February 2013. This document will be presented as a reference for sale and evaluation of construction consent targeting apartment complexes with more than 500 households, a typical size complex. This research was undertaken for predicting daylight environment and the energy load of each dwelling and incorporating this performance into the design process. 
The purpose is as follows: First, the daylight environment is analyzed according to the changes of floor level and building direction of the major two apartment shapes: Flat-type and L-type; Second, the energy consumption is calculated by predicting the thermal environment by simulation; Finally, the characteristics of each building shape are analyzed, and the design method of them was drawn for the optimal passive houses incorporating the environmental performance.

\subsection{Research Methods and Process}

Using simulations from ECOTECT analysis 2011, the morphological features of various apartments are drawn by lighting and thermal environment of each dwelling. The illumination is simulated with the conditions of both a cloudy and a sunny day and the distribution is shown on the plan. Energy efficiency is calculated according to the heating and cooling loads from the outside temperature by the weather conditions. This result was then compared according to the location and direction of each dwelling.

In total, daylight environment varies according to building direction in two shapes. These results included the performance of lighting and energy efficiency in each condition. They also explain the shape characteristics of passive apartment with a method to improve the daylight environment of each dwelling.

\section{The Keynote of Passive Design}

\subsection{Building Shape and Day Lighting}

The climate zone of South Korea located at the latitude $37^{\circ} \mathrm{N}$ belongs to " 4 " climate zone (mixed-humid) proposed ASHRAE standard 90.1-2007 [2]. In this humid continental and humid subtropical climate condition, it is important to use natural day lighting in the area of the south windows [3]. The south facing openings absorb the morning sunlight and more direct solar energy compared to other directions. A south facing space should be designed as the concept of open space planning. Thus, the sunlight enters deeply and widely inside the home, and air, heat and natural light are well circulated. Finally, the indoor temperature of the winter would rise by the natural solar energy, even though summer cooling load might be overloaded. Therefore, the depth of the room, the south-facing window area ratio and other conditions should vary with the building shape.

\subsection{Window and Shading Design}

Window design should reduce heat loss [4] and enhance the natural light. However, excessive overheating inside space should be limited. In addition, the lighting distribution needs to keep a balance between the south-facing window and all but south facing window. The illumination and energy efficiency of window are different depending on the U-value, window mullion detail, transmittance and the SHGC (solar heat gain coefficient) [5]. Therefore, all the windows on each side are designed to the optimal condition considering natural environment. For example, a SHGC of 0.719 in northwest Calgary of Canada is advisable to obtain high solar energy for the south-facing window. In addition, a U-value of 0.8 $\mathrm{W} / \mathrm{m}^{2} \cdot \mathrm{K}$ is recommended [6, 7]. These factors optimize the daylight and solar heat. On the other hand, the north, east and west-facing window should have the thermal insulating value (R-7.7) to decrease the solar heat and install a low SHGC (0.477) to reduce the absorption of the sun energy to be overheated by the low altitude [7]. In addition, maximizing the free cooling generates significant difference in energy consumption to minimize for an air conditioning unit. Therefore, a design strategy such as operable windows and high ceilings should be optimized for the natural convection, air circulation and cross ventilation [8].

\subsection{Passive House Design}

The passive housing design uses solar energy as integral design criteria. The passive house in South 
Korea can be more efficient use of solar energy than one first created in Germany, due to the lower latitude. The window design is important for passive house design to correspond to the daylight characteristics of each direction. In addition, the thermal performance of building envelopes such as walls should be optimized because a different performance is required depending on the climate [9].

At this time, heating load is five times higher than cooling load in South Korea, and plans should be designed so that as much sun energy as possible is received, heat can be easily transferred to open spaces while still preventing overheating. In the case of the north window which has relatively poor condition, the required degree of the heat loss and the room's sunlight should achieve a balance. Securing the air tightness for the windows and walls can also reduce the heat loss. Accordingly, heat fluctuation decreases and thermal comfort increases. In addition, the environment to minimize use of air conditioning units and heating energy usage should be kept.

\section{The Method for Performance Evaluation}

\subsection{Simulation for Evaluation of the Lighting Environment}

Two methods both DF (daylight factor) and LEED standard for lighting were used to measure the adequacy of the inside illumination changes depending on the weather [10]. DA (daylight autonomy) ${ }^{1}$ in the typical two standards of the dynamic simulation was considered. However, UDI (useful daylight illuminance) ${ }^{2}$ was not selected because setting the operating hours and the adequate illumination to work is more important factor for office building than housing [11-13].

First, as the evaluation standard of day lighting for

${ }^{1} \mathrm{DA}$ defined here is the ratio of the occupied period of time to satisfy a minimum illumination with only daylight. DA standards 500 lux longer hours from 7:00 am to 5:00 pm, and measuring the percentage of time of one year.

${ }^{2}$ UDI is a modification of daylight autonomy. This sets three illumination ranges as useful values: 0-100 lux, 100-2,000 lux and over 2,000 lux
LEED, the lighting environment was evaluated with both daylight factor in the overcast condition (Green building rating system version 2, 2005) and the illuminance of solar noon ${ }^{3}$ in the clear day of March or September 21 now in use (LEED EQ 8.1 rev2, 2009). Daylight factor is a measure of the internal natural daylight levels of overcast conditions for one year by ECOTECT. The illumination on September 21 in a clear day is measured by using the radiance linked from it. The reason to be used in conjunction with ECOTECT and radiance is that DF has no change depending on the direction because it has the standard of the overcast condition, i.e., cloudy day. On the other hand, the change according to the azimuth can be drawn on a sunny day by the radiance simulation. This research set the condition at 21 September solar noon (PM 12:26). Its result might be limited to describe the characteristics of the whole. However, it can be expected that the sun position of the autumnal equinox is close to the average position since the solar altitude is located in the middle of the point between the highest and the lowest season. In addition, it is used for measuring sunshine environment based on a clear day in LEED certification. The spacing of the measurement points was $60 \mathrm{~cm}$ which can obtain trustworthy results with the actual illumination $[14,15]$.

\subsection{Simulation for Evaluation of the Energy Consumption}

Despite energy plus makes it possible to provide the more realistic results [16], Autodesk's ECOTECT 2011 was used to evaluate the energy consumption. The reason is that it is better for calculating the amount of electricity rather than heating and cooling loads. This simulation is faster and easier so it fits the purpose of this paper to follow a relatively simple process for reviewing the building forms at the schematic or design development stage. However, the

\footnotetext{
${ }^{3}$ Solar noon: the point that the altitude of the sun is the highest.
} September 21 in Incheon, 12:26. 
measurement of the energy efficiency using it creates a lot of difference depending on setting the material property such as wall. Therefore, finding the optimal form is aimed at relative comparisons rather than absolute ones. The energy efficiency measures the heating and cooling loads, and the machine energy consumption of the home is not considered because a large part of it is determined by the performance of the machine rather than the architectural design. In addition, the energy produced by the renewable energy is not considered even though it is essential elements for aggressive energy-saving for the same reason [17].

\section{The Environmental Performance Evaluation of Various Apartment Types}

\subsection{Modeling Overview}

The architectural modeling was carried out by ECOTECT and set conditions such as weather and wall materials. Building modeling was performed based on the shape and area of typical types in the actual plan drawings and competition drawings. The two types: Flat-type and L-type were compared as South Korea's representative apartment types. The flat-type apartment was common until the late 1990s, and since 2000, various L-shape or Y-shape tower apartments have developed. In addition, there are also mixed type, both flat-type and tower-type. In addition, the three different floors: 1st floor (bottom), 10th floor (middle) and the 20th floor (top) were evaluated in the
20 stories building and Table 1 is an overview of the target model. The weather condition is based on Incheon's data provided in Energyplus weather format [18].

The material properties set the characteristics of the building's exterior walls. In walls, the U-value of 0.30 $\mathrm{W} / \mathrm{m}^{2} \cdot \mathrm{K}$ matched less than the criteria of the Central Region $\left(0.47 \mathrm{~W} / \mathrm{m}^{2} \cdot \mathrm{K}\right)$ recommended by the Ministry of Land, Transport and Maritime Affairs in South Korea. In windows, the Incheon's guideline 'the guidelines for green building design for a low-carbon, green growth' was referred for deciding the property [19]. According to these, U-value of window sets 1.7 $\mathrm{W} / \mathrm{m}^{2} \cdot \mathrm{K}$, which in Incheon is less than $1.8 \mathrm{~W} / \mathrm{m}^{2} \cdot \mathrm{K}$ and is on the basis of more than 2 grade in energy efficiency rating of windows and doors (1.4-2.1 $\left.\mathrm{W} / \mathrm{m}^{2} \cdot \mathrm{K}\right)$. SHGC was 0.81 and visible light transmittance was set to 0.647 . In the use of scenarios, there were four people usually sitting down and a mixed-mode system for heating and cooling of inside. An overview of the applied system of the building is seen in Table 2.

\subsection{Setting the Measurement Condition}

The apartment as a single building without neighboring buildings is not a realistic situation. In reality, most buildings are influenced by the shadow of another building. Most of cases have the negligible impact on the illumination and in some cases a critical impact on it [20, 21]. However, the placement of

Table 1 Overview of modeling.

\begin{tabular}{|c|c|c|c|}
\hline & Flat-type & \multicolumn{2}{|l|}{ L-type } \\
\hline Building shape & $\mathrm{W} M \quad \mathrm{E}$ & & \\
\hline Floor area & All : $129.3 \mathrm{~m}^{2}$ & A, D: $132.9 \mathrm{~m}^{2}$ & B, C: $128.3 \mathrm{~m}^{2}$ \\
\hline Height/stories & $2.8 \mathrm{~m} / 20$ stories & $2.8 \mathrm{~m} / 20$ stories & \\
\hline Total window area & $26.4 \mathrm{~m}^{2}$ & A, D: $26.5 \mathrm{~m}^{2}$ & B, C: $25.6 \mathrm{~m}^{2}$ \\
\hline Window to floor area ratio & $20 \%$ & $20 \%$ & \\
\hline South window to wall area ratio & $\begin{array}{l}43.7 \% \\
\text { (wall: } 38.9 \mathrm{~m}^{2} \text {, window: } 17 \mathrm{~m}^{2} \text { ) }\end{array}$ & $\begin{array}{l}\text { A, D: } 39.6 \%(w \\
\text { B, C: } 34.5 \% \text { (wa }\end{array}$ & $\begin{array}{l}2.3 \mathrm{~m}^{2} \text {, window: } 8.8 \mathrm{~m}^{2} \text { ) } \\
\left.3.1 \mathrm{~m}^{2} \text {, window: } 21.8 \mathrm{~m}^{2}\right)\end{array}$ \\
\hline
\end{tabular}


Table 2 Overview of the applied system.

\begin{tabular}{lll}
\hline Classification & \multicolumn{2}{c}{ Contents } \\
\hline & Wall & $0.30 \mathrm{~W} / \mathrm{m}^{2} \cdot \mathrm{K}$ \\
Wall-skin U-value & Window & $1.7 \mathrm{~W} / \mathrm{m}^{2} \cdot \mathrm{K}(\mathrm{SHGC}: 0.81)$ \\
& Slab on ground & $0.35 \mathrm{~W} / \mathrm{m}^{2} \cdot \mathrm{K}$ \\
& Slab between floors & $0.58 \mathrm{~W} / \mathrm{m}^{2} \cdot \mathrm{K}$ \\
& Roof & $0.206 \mathrm{~W} / \mathrm{m}^{2} \cdot \mathrm{K}$ \\
\hline \multirow{2}{*}{ Internal design condition } & Clothing & $0.4 \mathrm{clo}$ \\
& Humidity & $60 \%$ \\
& AIR speed & $0.5 \mathrm{~m} / \mathrm{s}$ \\
Infiltration rate & Lighting level & 500 lux (working plane: $70 \mathrm{~cm})$ \\
\hline \multirow{2}{*}{ Active system } & Air change rate & $0.25 \mathrm{ach}$ \\
& Wind sensitivity & Reasonably protected $(0.25$ ach) \\
\hline
\end{tabular}

the building would vary depending on the building shape or the area shape. Hence, the scope of the study was limited for these reasons, the purpose of the study is to derive the characteristics of each building regardless of shading effects due to nearby buildings. Thus the daylight conditions of each dwelling were analyzed depending on various building orientation. Five different angles of rotation axis were chosen, as shown in Table 3: $0^{\circ}$ (south-facing), N15E $\left(-15^{\circ}\right)$, $\mathrm{N} 30 \mathrm{E}\left(-30^{\circ}\right), \mathrm{N} 45 \mathrm{E}\left(-45^{\circ}\right)$ and $\mathrm{N} 45 \mathrm{~W}\left(45^{\circ}\right)$. The weather data in Incheon provided by Energyplus was used for analysis of illumination and energy efficiency.

\subsection{The Simulation of Illumination}

\subsubsection{The Flat Type Building}

The useful illumination has to be more than $2 \%$ of daylight factor [22] and the shading is needed in more than DF $5 \%$ due to glare and solar gain. Table 4 shows that the side dwellings of flat-type building

Table 3 Overview of the measurement point (September 21, 9:00-17:00).

\begin{tabular}{llll}
\multicolumn{2}{c}{ Flat type } & L type & Rotation of axes \\
\hline & & &
\end{tabular}

Table 4 Daylight simulation of the flat-type apartment.

\begin{tabular}{lclllllll}
\hline \multirow{2}{*}{ Location of units } & \multirow{2}{*}{ Floor No. } & \multirow{2}{*}{ DF (\%) } & \multirow{2}{*}{ DA (\%) } & \multicolumn{5}{c}{ Illumination (September 21 PM 12:26) } \\
\cline { 6 - 9 } & & & & N45W & 0 & N15E & N30E & N45E \\
W Unit & $1 \mathrm{~F}$ & 4.85 & 82.28 & $4,303.85$ & $4,831.48$ & $4,656.14$ & $4,653.93$ & $4,076.84$ \\
(W-west) & $10 \mathrm{~F}$ & 5.58 & 86.02 & 4,437 & 5,034 & 4,843 & 4,823 & $4,201.39$ \\
& $20 \mathrm{~F}$ & 5.69 & 86.56 & $4,688.5$ & $5,410.5$ & $5,196.56$ & $5,141.4$ & $4,462.9$ \\
M Unit & $1 \mathrm{~F}$ & 3.63 & 61.73 & $4,040.51$ & $4,791.71$ & $4,705.88$ & $4,713.03$ & $4,143.12$ \\
(M & $10 \mathrm{~F}$ & 3.84 & 67.35 & $4,195.96$ & $5,034.13$ & $4,957.37$ & $4,915.71$ & $4,289.59$ \\
-middle) & $20 \mathrm{~F}$ & 3.87 & 67.52 & $4,471.1$ & $5,419.26$ & $5,293.43$ & $5,236.62$ & $4,548.28$ \\
& $1 \mathrm{~F}$ & 4.02 & 71.25 & $4,131.34$ & $4,779.73$ & $4,601.29$ & $4,786.79$ & $4,131.76$ \\
E Unit & $10 \mathrm{~F}$ & 4.53 & 79.02 & $4,271.32$ & 5,025 & $4,850.85$ & $4,976.89$ & $4,281.14$ \\
(E-east) & $20 \mathrm{~F}$ & 4.58 & 79.29 & $4,540.47$ & $5,388.61$ & $5,186.17$ & $5,311.43$ & $4,533.76$ \\
\hline
\end{tabular}


have better distribution. To be specific, since dwellings with higher daylight factor are located on the west more, the highest internal natural lighting level was likely to be located from the west. However, illuminations for September 21 at solar noon were roughly alike regardless of the dwelling's different location.

As shown in Fig. 1, according to floor level, the difference of DF between 10th and 20th floor dropped sharply as its $9.8-15 \%$ between 1 st and 10 th one. In addition, the DA's one did its 3-14\% between 1 st and 10th one. The illumination for September 21 with from -30 to -45 degrees declined sharply when compared with the rotation angle of -30-0 degrees. That is the difference between -45 to -30 degrees in 1st floor increased by 3.25, 7.24 and 3.53 times more than it of $-30 \sim 0^{\circ}$, respectively. On the other hand, the difference between 45 and -45 degrees is not that big. The authors can know that the illumination between east and west with the same angular size is analogous; that is, the distribution of lighting is expected to be symmetrical arrangement. As a result, the illumination of 1 st floor would have the poor condition if the window area is the same as that of upper level. In addition, it would be better that south-facing buildings rotate less than 30 degrees. However, if rotating the building by over 30 degrees were so inevitable, enough window area should be installed.

\subsubsection{The L-Type Building}

Each dwelling had relatively small DF gap. To be specific, the east-locating units (A and B) had the smallest one. Side units (A and D) have relatively high DF than middle units ( $B$ and $C$ ). As shown in Table 5, in the change of DF from 1st to 20th floor, A, $\mathrm{B}$ and $\mathrm{D}$ almost scaled $8 \%$ up and $\mathrm{C}$ formed a nearly horizontal line. A or B unit increased rapidly on 10th floor while average increase of around $8 \%$. In addition, the changing amount of DA is similar to that of DF.

However, considerable differences of the illumination at September 21, solar noon on a sunny day existed between units. For instance, according to the building rotation, $\mathrm{B}$ and $\mathrm{C}$ unit totally have higher illumination and big changing range. Moreover, in A and $\mathrm{B}$ unit, 45 degrees of the rotation angle was the lowest point and it gradually increased to the point of minus 45 degrees; in $\mathrm{C}$ and $\mathrm{D}$ unit, the illumination data decreased from minus 45 degrees contrary to previous results as given in Fig. 2.

\subsection{Simulation Related to Energy Efficiency}

\subsubsection{The Flat Type Building}

Heating and cooling loads decide consumption of thermal energy as a big part of residential buildings. Table 6 shows energy loads of flat type apartment. As

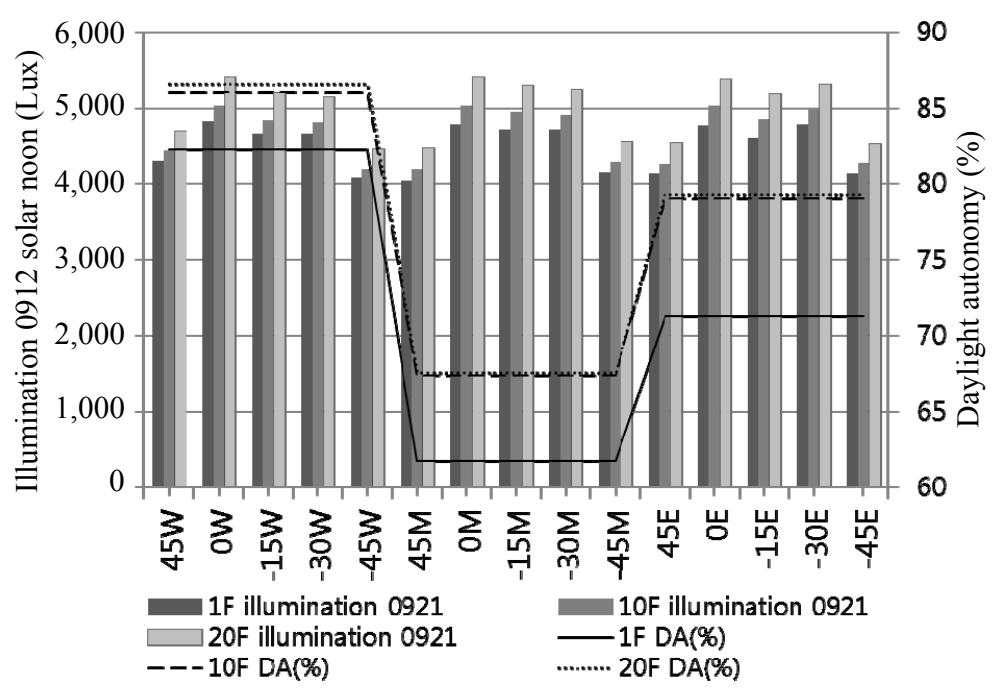

Fig. 1 Distribution of daylight in the flat-type apartment. 
Table 5 Daylight simulation of the L-type apartment.

\begin{tabular}{lclllllll}
\hline \multirow{2}{*}{ Location of units } & \multirow{2}{*}{ Floor No. } & DF $(\%)$ & \multirow{2}{*}{ DA $(\%)$} & \multicolumn{5}{c}{ Illumination (September 21 PM 12:26) } \\
\cline { 6 - 9 } A Unit & $1 \mathrm{~F}$ & 4.99 & 79.62 & 818.53 & $1,794.85$ & $2,099.2$ & $3,034.78$ & $2,907.85$ \\
& $10 \mathrm{~F}$ & 5.54 & 82.75 & 865.64 & $1,908.63$ & $2,248.8$ & $3,213.63$ & $3,087.19$ \\
& $20 \mathrm{~F}$ & 5.8 & 84.7 & 834.52 & $1,835.48$ & $2,163.28$ & $3,109.49$ & $3,006.84$ \\
B Unit & $1 \mathrm{~F}$ & 4.84 & 78.7 & $1,892.05$ & 4,225 & $5,937.26$ & $6,204.23$ & $6,356.21$ \\
& $10 \mathrm{~F}$ & 5.49 & 83.44 & $1,997.05$ & $4,500.18$ & $6,308.7$ & $6,618.29$ & $6,770.44$ \\
& $20 \mathrm{~F}$ & 5.61 & 84.01 & $1,939.76$ & $4,353.05$ & $6,104.03$ & $6,393.25$ & $6,552.23$ \\
C Unit & $1 \mathrm{~F}$ & 4.77 & 76.76 & $6,745.26$ & $4,760.36$ & $3,927.12$ & $2,165.39$ & $1,985.31$ \\
& $10 \mathrm{~F}$ & 4.77 & 75.85 & $7,149.03$ & $4,851.06$ & $3,942.49$ & $2,096.44$ & $1,875.7$ \\
& $20 \mathrm{~F}$ & 4.85 & 76.24 & $6,881.21$ & $4,677.39$ & $3,886.37$ & $2,201.78$ & $1,825.61$ \\
D Unit & $1 \mathrm{~F}$ & 5.56 & 83.94 & $3,024.7$ & $1,970.32$ & $1,664.45$ & 932.06 & 854.08 \\
& $10 \mathrm{~F}$ & 6.02 & 85.78 & 3,086 & $1,921.15$ & $1,691.66$ & 954.9 & 873.84 \\
& $20 \mathrm{~F}$ & 6.53 & 88 & $3,113.13$ & $2,011.98$ & $1,691.9$ & 939.91 & 868.14 \\
\hline
\end{tabular}

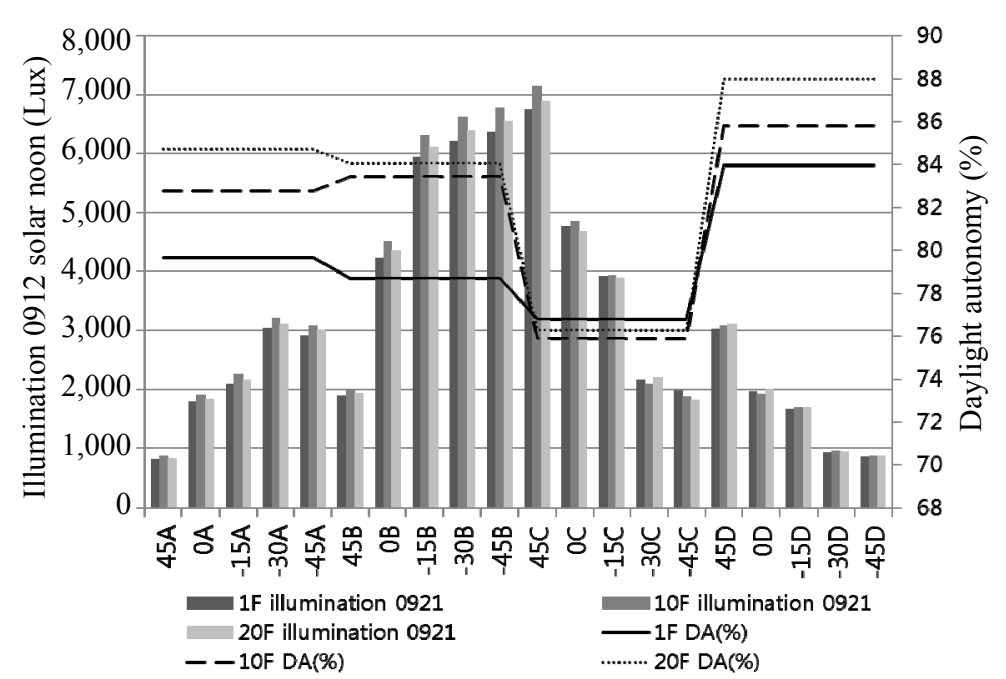

Fig. 2 Distribution of daylight in the L-type apartment.

can be seen, the total loads of middle story tends to be lower and those of the bottom or top floor facing on the outside are higher. In the heating load on the 1st floor, there was a significant difference between east and west unit ( $W_{0}=63,782 ; E_{0}=60,732$ ), however, there was a slight difference in that of 10th or 20th floor (10F: $\left.W_{15}=61,843 ; E_{15}=62,055\right)$. In addition, the difference between $\mathrm{E}$ and $\mathrm{M}$ unit in 0 degrees is 4 times more than it between $\mathrm{W}$ and $\mathrm{M}$ unit, whereas, in 20th floor it is reversed. The -15 degrees among five cases was the lowest energy load, which is related to the optimal minus 5 degrees (N5E) in the climate condition of Incheon with ECOTECT simulation. When the angle from minus 15 degrees increased or decreased, total load of units was mostly higher as shown in Fig. 3. In addition, the heating load of the middle story is relatively lower because top and bottom floors face on the outdoor air instead of other dwellings, however, this factor is not absolute, since the insulation design method of bottom and top slab is most important valuable of setting the difference of energy performance.

\subsubsection{The L-type Building}

Cooling load remained more or less constant even though the azimuth angle was changed, however, heating load had more significant change. Energy loads of the east dwellings (A and B) were smaller than those of the west ones (C and D) as shown in Fig. 4. The case of $\mathrm{B}$ unit showed the highest direct solar ratio and the relatively lower energy loads in total 
Table 6 Energy simulation of the flat-type apartment.

\begin{tabular}{|c|c|c|c|c|c|c|c|}
\hline Location & Story & Azimuth & N45W & 0 & N15E & N30E & $\mathrm{N} 45 \mathrm{E}$ \\
\hline \multirow{12}{*}{ W } & \multirow{4}{*}{$1 \mathrm{~F}$} & Total $\left(\mathrm{wh} / \mathrm{m}^{2}\right)$ & 68,252 & 66,616 & 66,521 & 66,741 & 67,228 \\
\hline & & Heating & 65,191 & 63,782 & 63,688 & 63,883 & 64,315 \\
\hline & & Cooling & 3,061 & 2,834 & 2,833 & 2,858 & 2,913 \\
\hline & & Direct sol (\%) & 15.7 & 16.9 & 17.1 & 17.2 & 16.9 \\
\hline & \multirow{4}{*}{$10 \mathrm{~F}$} & Total $\left(w h / m^{2}\right)$ & 62,569 & 60,933 & 60,847 & 61,096 & 61,583 \\
\hline & & Heating & 59,188 & 57,763 & 57,676 & 57,880 & 58,312 \\
\hline & & Cooling & 3,380 & 3,170 & 3,172 & 3,216 & 3,271 \\
\hline & & Direct sol (\%) & 16.1 & 17.3 & 17.6 & 17.6 & 17.3 \\
\hline & \multirow{4}{*}{$20 \mathrm{~F}$} & Total $\left(\mathrm{wh} / \mathrm{m}^{2}\right)$ & 66,630 & 64,991 & 64,900 & 65,131 & 65,629 \\
\hline & & Heating & 63,296 & 61,843 & 61,756 & 61,953 & 62,390 \\
\hline & & Cooling & 3,334 & 3,148 & 3,144 & 3,178 & 3,240 \\
\hline & & Direct sol (\%) & 15.9 & 17.1 & 17.4 & 17.5 & 17.1 \\
\hline \multirow{12}{*}{ M } & \multirow{4}{*}{$1 \mathrm{~F}$} & Total $\left(\mathrm{wh} / \mathrm{m}^{2}\right)$ & 67,916 & 67,155 & 67,123 & 67,296 & 67,602 \\
\hline & & Heating & 65,441 & 64,832 & 64,780 & 64,880 & 65,102 \\
\hline & & Cooling & 2,476 & 2,324 & 2,342 & 2,416 & 2,500 \\
\hline & & Direct sol (\%) & 14.7 & 14.1 & 14.4 & 14.9 & 15.2 \\
\hline & \multirow{4}{*}{$10 \mathrm{~F}$} & Total $\left(\mathrm{wh} / \mathrm{m}^{2}\right)$ & 62,285 & 61,515 & 61,494 & 61,671 & 61,968 \\
\hline & & Heating & 59,027 & 58,418 & 58,377 & 58,479 & 58,692 \\
\hline & & Cooling & 3,257 & 3,098 & 3,116 & 3,192 & 3,276 \\
\hline & & Direct sol (\%) & 12.8 & 12.3 & 12.6 & 13 & 13.3 \\
\hline & \multirow{4}{*}{$20 \mathrm{~F}$} & Total $\left(\mathrm{wh} / \mathrm{m}^{2}\right)$ & 66,347 & 65,596 & 65,577 & 65,742 & 66,036 \\
\hline & & Heating & 63,147 & 62,540 & 62,495 & 62,592 & 62,803 \\
\hline & & Cooling & 3,201 & 3,056 & 3,082 & 3,150 & 3,233 \\
\hline & & Direct sol (\%) & 12.7 & 12.1 & 12.4 & 12.9 & 13.1 \\
\hline \multirow{12}{*}{$\mathrm{E}$} & \multirow{4}{*}{$1 \mathrm{~F}$} & Total $\left(\mathrm{wh} / \mathrm{m}^{2}\right)$ & 65,126 & 63,606 & 63,557 & 63,843 & 64,359 \\
\hline & & Heating & 62,045 & 60,732 & 60,698 & 60,952 & 61,431 \\
\hline & & Cooling & 3,081 & 2,874 & 2,859 & 2,891 & 2,928 \\
\hline & & Direct sol (\%) & 16 & 17.3 & 17.6 & 17.6 & 17.3 \\
\hline & \multirow{4}{*}{$10 \mathrm{~F}$} & Total $\left(\mathrm{wh} / \mathrm{m}^{2}\right)$ & 62,673 & 61,159 & 61,130 & 61,430 & 61,956 \\
\hline & & Heating & 59,284 & 57,982 & 57,948 & 58,206 & 58,679 \\
\hline & & Cooling & 3,388 & 3,177 & 3,182 & 3,224 & 3,278 \\
\hline & & Direct sol (\%) & 16 & 17.3 & 17.6 & 17.6 & 17.3 \\
\hline & \multirow{4}{*}{$20 \mathrm{~F}$} & Total $\left(\mathrm{wh} / \mathrm{m}^{2}\right)$ & 66,741 & 65,210 & 65,173 & 65,461 & 65,994 \\
\hline & & Heating & 63,392 & 62,055 & 62,018 & 62,269 & 62,748 \\
\hline & & Cooling & 3,349 & 3,155 & 3,154 & 3,193 & 3,246 \\
\hline & & Direct sol (\%) & 15.8 & 17.1 & 17.4 & 17.5 & 17.1 \\
\hline
\end{tabular}
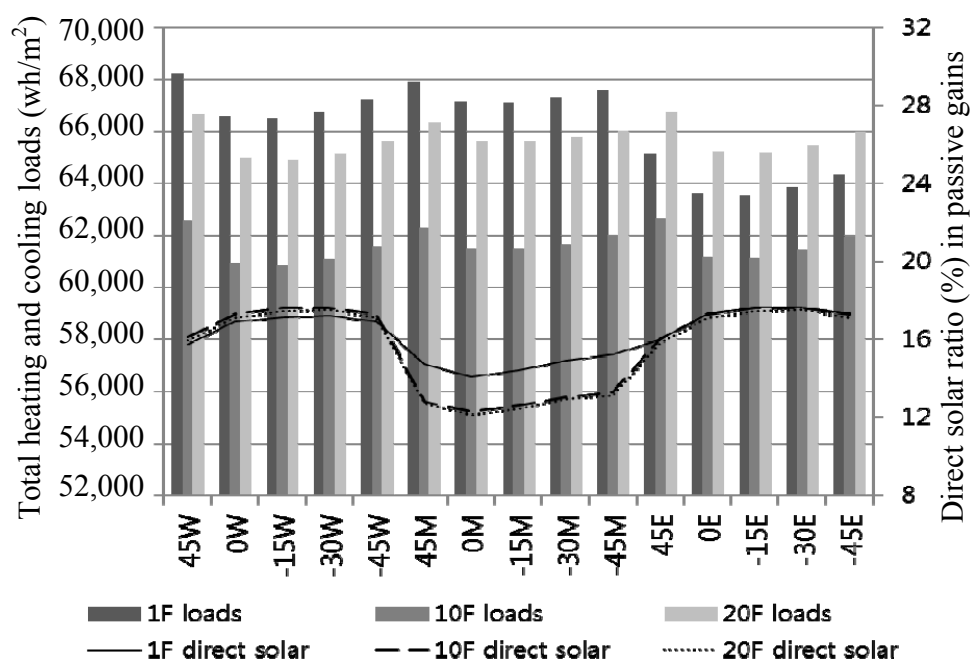

Fig. 3 Variation of thermal load with different azimuth (flat-type apartment). 


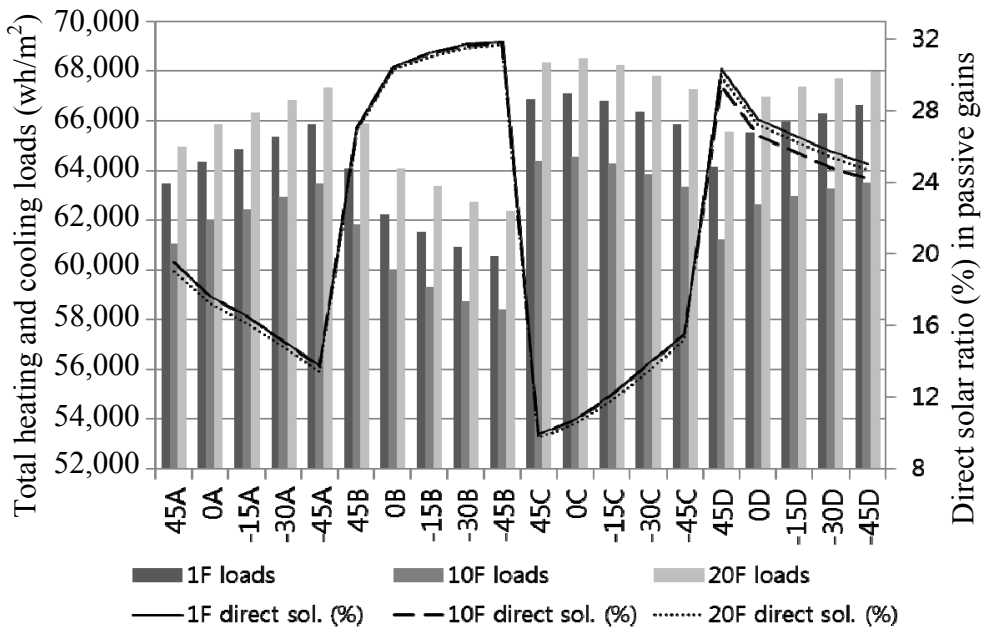

Fig. 4 Variation of thermal load with different azimuth (L-type apartment).

like middle units of flat type building. In addition, it demonstrated that DF or DA, i.e., the internal natural light level was significantly higher, since the illumination and the amount of solar energy through windows is enough. It differed very markedly from $\mathrm{C}$ unit with the lowest direct solar ratio. In addition, B and $\mathrm{C}$ unit showed the similar change pattern in which total load decreased from 45 degrees. On the other hand, total load of A or D increased gradually. In 45 degrees facing on southwest, the gap of energy loads between middle ( $\mathrm{B}$ and $\mathrm{C}$ ) and the side units ( $\mathrm{A}$ and $\mathrm{D}$ ) was smaller and the value was more than other rotation angles as shown in Table 7. According to the rotation of main axis, the unit with the lowest total load moved to other location because the main direction of each dwelling changed. Also, middle story units tend to have lower loads like as in the flat type building. However, the higher insulation levels would make up for the weak points.

\subsection{The Environmental Performance Evaluation}

\subsubsection{The Evaluation of Daylight Environment}

The difference in the azimuth and the floor level was analyzed with the sunshine environment evaluation. First, the changes of daylight factor showed the fact that they in the flat-type apartment form lines with the similar slope on the graph as shown in Fig. 5. The daylight factor actually represents internal natural light levels regardless of the changing climates with a great deal of sunlight. On the other hand, the L-type one showed that the change of $\mathrm{A}$ and $\mathrm{B}$ unit located on the east was analogous to the west unit of flat-type apartment, whereas, that of $\mathrm{C}$ and $\mathrm{D}$ unit forms close to a straight line. This explained that they had a constant ratio depending on floor levels. Moreover, side units (A and D) had a bigger change like them in the flat one.

Also, in the illumination on September 21 of the flat-type, the units had smaller difference according to the rotation of the building. However, the L-type apartment made greatly bigger difference of the illumination on September 21 between units. In addition, in the change pattern of the illumination, those of the flat-type had similarities, whereas, those of the L-type varied depending on the location of units. This was because all dwellings in the flat-type apartment have the same azimuth based on the solar orientation of the building; whereas, those of L-type one had the various azimuth.

This explained shape characteristic for apartment as follows: First, the flat type building could be formed with vastly different conditions. That is the location of units would decide the favorable environment regardless of the change of seasons or the building arrangement; Second, the L-type apartment could provide the internal natural daylight not differing 
much from other units, especially on 1st floor. However, according to the season, each unit would have very different daylight environment. Likewise, the daylight environment of each dwelling was influenced by the shape of buildings. Thus, it would change the design method for building skin. These form-determining factors beyond the window area would depend on installing the sunshade, the U-value of windows, SHGC, and the location and shape of windows.

Table 7 Energy simulation of the L-type apartment.

\begin{tabular}{|c|c|c|c|c|c|c|c|}
\hline Location & Story & Azimuth & N45W & 0 & $\mathrm{~N} 15 \mathrm{E}$ & $\mathrm{N} 30 \mathrm{E}$ & $\mathrm{N} 45 \mathrm{E}$ \\
\hline \multirow{12}{*}{ A } & \multirow{4}{*}{$1 \mathrm{~F}$} & Total $\left(\mathrm{wh} / \mathrm{m}^{2}\right)$ & 63,459 & 64,341 & 64,818 & 65,320 & 65,846 \\
\hline & & Heating & 60,499 & 61,463 & 61,969 & 62,501 & 63,054 \\
\hline & & Cooling & 2,960 & 2,878 & 2,849 & 2,820 & 2,793 \\
\hline & & Direct sol (\%) & 19.5 & 17.6 & 16.5 & 15.1 & 13.7 \\
\hline & \multirow{4}{*}{$10 \mathrm{~F}$} & Total $\left(\mathrm{wh} / \mathrm{m}^{2}\right)$ & 61,033 & 61,955 & 62,434 & 62,925 & 63,443 \\
\hline & & Heating & 57,755 & 58,719 & 59,219 & 59,740 & 60,285 \\
\hline & & Cooling & 3,278 & 3,236 & 3,215 & 3,186 & 3,158 \\
\hline & & Direct sol (\%) & 19.5 & 17.6 & 16.5 & 15.1 & 13.7 \\
\hline & \multirow{4}{*}{$20 \mathrm{~F}$} & Total $\left(\mathrm{wh} / \mathrm{m}^{2}\right)$ & 64,928 & 65,821 & 66,297 & 66,800 & 67,307 \\
\hline & & Heating & 61,577 & 62,523 & 63,019 & 63,539 & 64,085 \\
\hline & & Cooling & 3,350 & 3,298 & 3,278 & 3,261 & 3,223 \\
\hline & & Direct sol (\%) & 19 & 17.2 & 16.1 & 14.8 & 13.4 \\
\hline \multirow{12}{*}{ B } & \multirow{4}{*}{$1 \mathrm{~F}$} & Total $\left(\mathrm{wh} / \mathrm{m}^{2}\right)$ & 64,075 & 62,209 & 61,506 & 60,902 & 60,560 \\
\hline & & Heating & 59,677 & 57,814 & 57,174 & 56,656 & 56,400 \\
\hline & & Cooling & 4,398 & 4,395 & 4,332 & 4,246 & 4,160 \\
\hline & & Direct sol (\%) & 27 & 30.4 & 31.2 & 31.7 & 31.8 \\
\hline & \multirow{4}{*}{$10 \mathrm{~F}$} & Total $\left(\mathrm{wh} / \mathrm{m}^{2}\right)$ & 61,816 & 60,007 & 59,295 & 58,707 & 58,394 \\
\hline & & Heating & 57,162 & 55,333 & 54,700 & 54,192 & 53,940 \\
\hline & & Cooling & 4,654 & 4,674 & 4,595 & 4,514 & 4,454 \\
\hline & & Direct sol (\%) & 27 & 30.4 & 31.2 & 31.6 & 31.8 \\
\hline & \multirow{4}{*}{$20 \mathrm{~F}$} & Total $\left(\mathrm{wh} / \mathrm{m}^{2}\right)$ & 65,865 & 64,058 & 63,352 & 62,696 & 62,334 \\
\hline & & Heating & 61,104 & 59,263 & 58,616 & 58,084 & 57,802 \\
\hline & & Cooling & 4,761 & 4,795 & 4,736 & 4,612 & 4,532 \\
\hline & & Direct sol $(\%)$ & 26.9 & 30.3 & 31 & 31.5 & 31.7 \\
\hline \multirow{12}{*}{$\mathrm{C}$} & \multirow{4}{*}{$1 \mathrm{~F}$} & Total $\left(\mathrm{wh} / \mathrm{m}^{2}\right)$ & 66,828 & 67,053 & 66,775 & 66,351 & 65,819 \\
\hline & & Heating & 63,866 & 63,865 & 63,508 & 62,987 & 62,390 \\
\hline & & Cooling & 2,963 & 3,188 & 3,268 & 3,363 & 3,428 \\
\hline & & Direct sol $(\%)$ & 9.9 & 10.7 & 12.1 & 13.8 & 15.5 \\
\hline & \multirow{4}{*}{$10 \mathrm{~F}$} & Total $\left(\mathrm{wh} / \mathrm{m}^{2}\right)$ & 64,359 & 64,529 & 64,260 & 63,823 & 63,313 \\
\hline & & Heating & 61,066 & 61,062 & 60,708 & 60,202 & 59,619 \\
\hline & & Cooling & 3,293 & 3,467 & 3,552 & 3,621 & 3,693 \\
\hline & & Direct sol $(\%)$ & 9.9 & 10.7 & 12.1 & 13.8 & 15.5 \\
\hline & \multirow{4}{*}{$20 \mathrm{~F}$} & Total $\left(\mathrm{wh} / \mathrm{m}^{2}\right)$ & 68,316 & 68,484 & 68,209 & 67,783 & 67,250 \\
\hline & & Heating & 64,944 & 64,950 & 64,595 & 64,088 & 63,504 \\
\hline & & Cooling & 3,372 & 3,535 & 3,614 & 3,695 & 3,746 \\
\hline & & Direct sol $(\%)$ & 9.7 & 10.5 & 11.8 & 13.4 & 15.2 \\
\hline \multirow{12}{*}{$\mathrm{D}$} & \multirow{4}{*}{$1 \mathrm{~F}$} & Total $\left(\mathrm{wh} / \mathrm{m}^{2}\right)$ & 64,119 & 65,522 & 65,938 & 66,273 & 66,581 \\
\hline & & Heating & 59,889 & 61,380 & 61,816 & 62,169 & 62,479 \\
\hline & & Cooling & 4,231 & 4,142 & 4,122 & 4103 & 4,101 \\
\hline & & Direct sol (\%) & 30.3 & 27.5 & 26.6 & 25.7 & 25 \\
\hline & \multirow{4}{*}{$10 \mathrm{~F}$} & Total $\left(\mathrm{wh} / \mathrm{m}^{2}\right)$ & 61,210 & 62,583 & 62,959 & 63,250 & 63,508 \\
\hline & & Heating & 56,752 & 58,187 & 58,583 & 58,891 & 59,162 \\
\hline & & Cooling & 4,458 & 4,396 & 4,377 & 4,359 & 4,347 \\
\hline & & Direct sol (\%) & 29.4 & 26.6 & 25.7 & 24.8 & 24.2 \\
\hline & \multirow{4}{*}{$20 \mathrm{~F}$} & Total $\left(w h / \mathrm{m}^{2}\right)$ & 65,539 & 66,934 & 67,344 & 67,672 & 67,969 \\
\hline & & Heating & 60,951 & 62,398 & 62,826 & 63,173 & 63,483 \\
\hline & & Cooling & 4,588 & 4,536 & 4,517 & 4,499 & 4,486 \\
\hline & & Direct sol (\%) & 29.9 & 27.2 & 26.3 & 25.4 & 24.7 \\
\hline
\end{tabular}




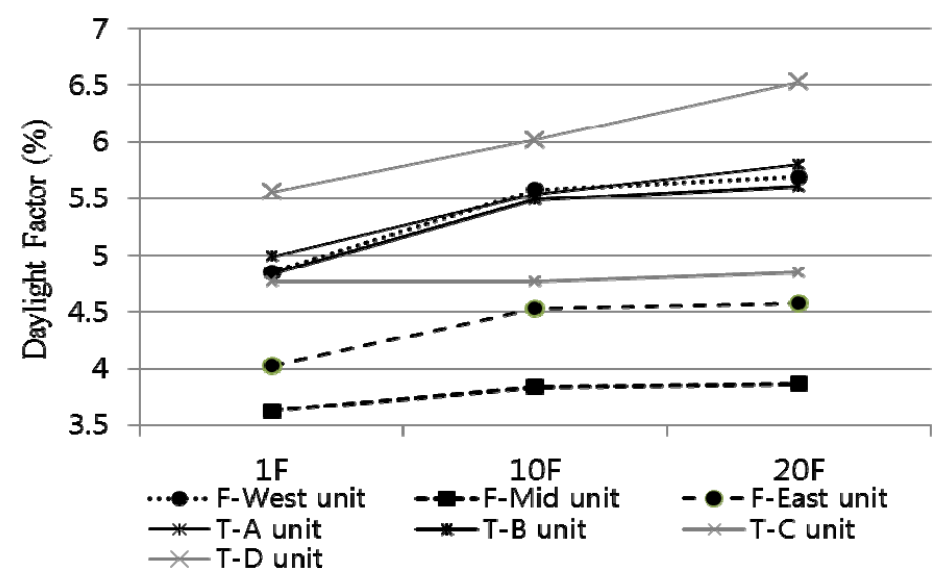

Fig. 5 Natural daylight levels on different floor level.

\subsubsection{The Evaluation of Energy Consumption}

Heating and cooling loads were measured for prediction of the energy consumption. The ratio of direct solar gains showed the direct impact of sunlight as the element affecting the thermal environment. Simulation results by ECOTECT showed that the change of energy loads according to the floor level was relatively bigger than the azimuth. Units in the middle story have the lowest energy load in common. In the case of flat building, total load of west units with minus 15 degrees, i.e., the azimuth $345^{\circ}$ was the lowest. In L-type building, the west middle units, B with minus 45 degrees, i.e., the azimuth $315^{\circ}$ had the lowest ones. The likely reason is that the ratio of direct solar gains is high and the azimuth is optimized for catching energy from the Sun. In addition, the results of units in the flat type were symmetric with respect to the point of 0 or 15 degrees, whereas, there is a huge difference between east and west units in L-type one. Moreover, as shown in Table 7 given previously, there were substantial changes depending on the building rotation. The result of flat apartment would be shown as in Fig. 6. First, the energy changing pattern between units appeared generally similar. The difference of total load between the east and west unit was not that big and they had better condition in the daylight factor. However, the difference of total load between 1st and 10th floor was considerable. In this sense, the units under 10th floor had a relatively poor condition in the environmental

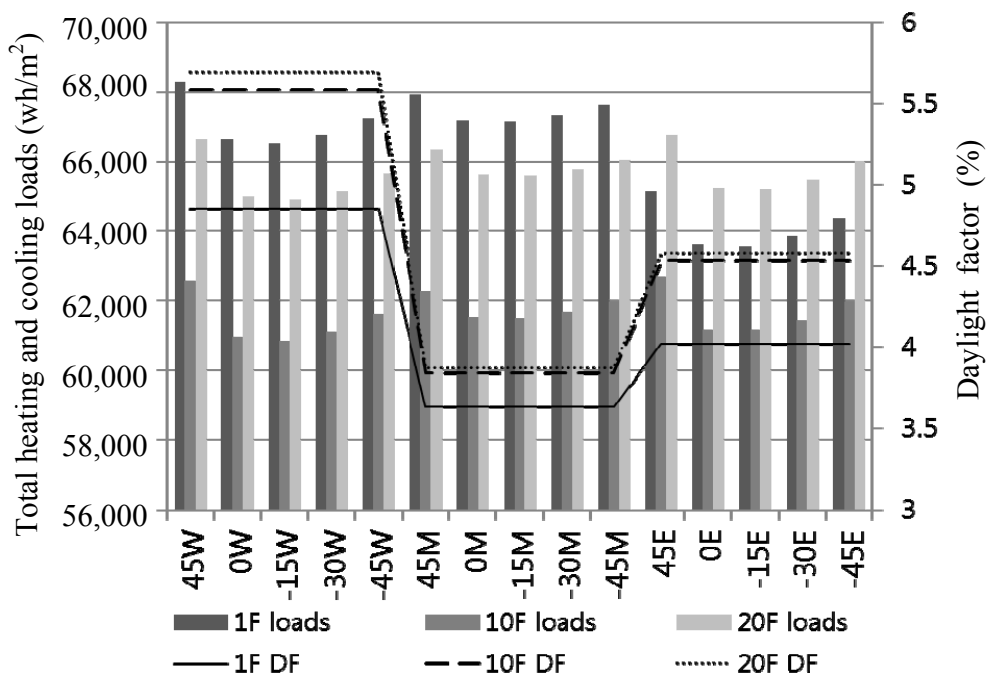

Fig. 6 Variation of environmental performance with different azimuth (flat-type apartment). 


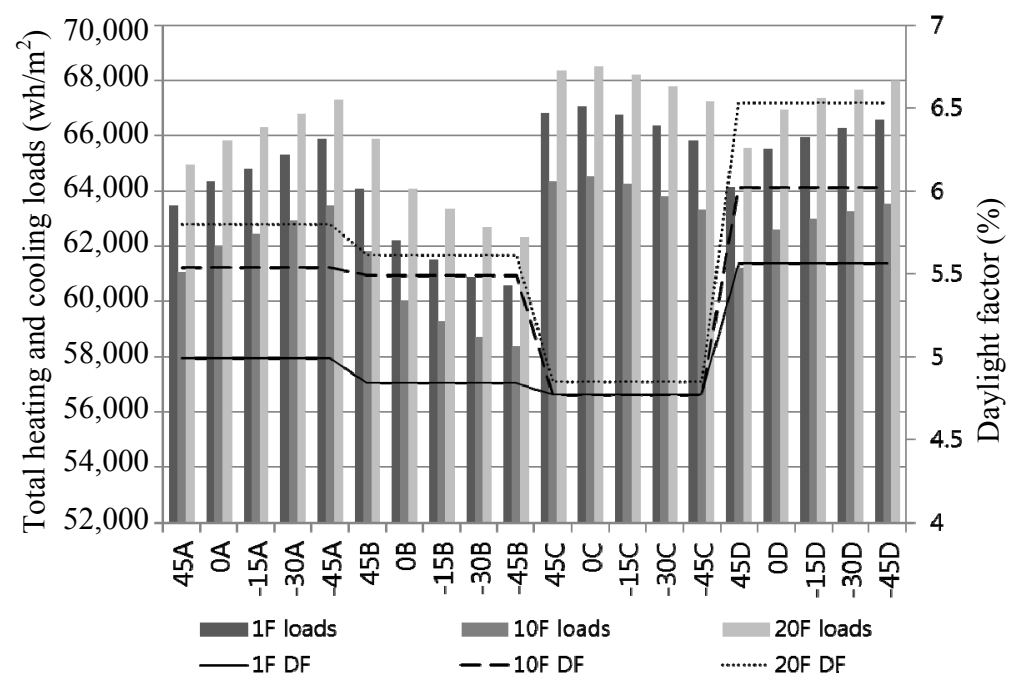

Fig. 7 Variation of environmental performance with different azimuth (L-type apartment).

performance. The daylight level also had a relatively big difference between 1st and 10th floor. It showed that the amount of solar gain between over and under 10th floor was actually different.

Fig. 7 presents the result of L-type apartment with different azimuth. There were the significant difference of energy loads depending on the azimuth and location of each unit. However, the change of floor level made smaller difference than it in flat-type apartment. In addition, it did not interrelate with the change of daylight level which sharply increased from 1st to 10th floor in the A and B unit and incremented to 20th floor in the $\mathrm{C}$ and $\mathrm{D}$ unit. As a result, contrary to popular belief, B unit facing south-west totally had the best level, while $\mathrm{C}$ unit facing south-east to was the worst part in both daylight and energy-saving.

To achieve the optimal building design, the condition which direction each unit faces on and how much the gap between them appears in the same building should be considered. In addition, the higher insulation performance is indispensable for decreasing thermal load, and then proper window area and shading installation could enhance the energy efficiency. Likewise, a design method for the environmental improvement of dwellings with relatively poor conditions must be carefully considered.

\section{Discussion and Conclusions}

This study has confirmed that the morphological features of the apartment building affect energy consumption and comfort for occupants. They can be improved by a variety of conditions such as inside illumination, the shape and size of buildings and windows as results of lots of previous researches have shown. In addition, the environmental difference of each unit is analyzed by the simulation depending on the apartment shape. The design with optimized environmental performance has to follow a process where the performance could be predicted and improved by using the simulation. However, the current simulation tools are limited in that it is difficult to check how the design results are close to the actual extent and which conditions are involved under simulated results. Thus through the comparative method in two types of the apartment building, the daylight environment and energy performance of each unit has been examined.

Conclusions are drawn as follows: First, the optimal design of the flat type apartment can be fixed more efficiently, however, that of the L-type one is flexible depending on the site condition. In the flat type, the daylight condition shows more consistent pattern of change depending on the rotation and elevation of the building. Moreover, in the energy consumption, the 
elevation is more decisive than the azimuth. Units on the middle story have lower energy loads than them on the top or bottom floor. Thus each units of middle story has the lowest energy load with the different azimuth. To be specific, the middle story with $0-15^{\circ}$ azimuth has the lowest one. In the internal natural daylight level, i.e., DF, the higher floor in the building, the more differences between edge and middle units happen, while there are small change in the vertical line at the same location. Therefore, the flat-type building can set the $0-15^{\circ}$ azimuth for the optimal arrangement. On the other hand, in L-type apartment, the daylight condition changes with different patterns of each unit according to the rotation and elevation of the building. In addition, the energy load has more change amount than that in the flat type according to the building rotation, whereas, there was a smaller change depending on the elevation. Therefore, the various arrangement methods in L-type depending on the site condition could be considered for the better condition of all units.

Second, when the building's rotation angle increases from -45 to 45 degrees, the best unit in the flat apartment remains the same, however, that in the L-type one alters significantly. In flat-type, the energy loads did not appear differently in line with the unit location, whereas, the illumination increased in the unit located on the side and upper part. Therefore, units in the middle of the flat apartment should have relatively large window area than the end ones in order to get enough daylight. In addition, the top or bottom slab of the building should install the high performance insulation for reducing the thermal load. In L-type, the changing pattern of environmental performance shown in Fig. 7 varies greatly depending on the unit's location. The azimuth made results of the thermal load greatly different. However, there was smaller difference depending on the floor level in terms of indoor thermal environment and comfort of the units. Therefore the horizontal position and the solar azimuth angle have a decisive effect on the unit's environmental performance in L-type building.

In total, the facade design should depend partly on the result of simulation in order to design the passive house with optimized environmental performance. If passive houses were more common in reality and most design processes were integrated to check and develop the energy efficiency, errors and complexity of the simulation could be improved gradually, and the optimized design be drawn more easily. In addition, the most common condition is that other building's shadow affects illumination and temperature inside buildings. From here, future lines of research could both simulate real-world conditions adequately, as well as understand the effect of building arrangement on environmental performance. As a result, the current design problem that the facade of apartments has the uniformly repetitive patterns would resolve itself. The cost of construction could increase in this process. However, if money on their energy bills could be saved by these designs, it could be a well-founded investment.

\section{References}

[1] Seoul City Hall, Building Energy Consumption Regulations for Total Amount, http://citybuild.seoul.go.kr (accessed Mar. 3, 2012).

[2] ANSI/ASRAE/IESNA Standard 90.1-2007, Energy Standard for Buildings Except Low-Rise Residential Buildings, 2007.

[3] Windows and Doors Design Guidelines for Building Energy-Saving, Ministry of Land, Transport and Maritime Affairs, July 2012, pp. 8-55.

[4] J. Cheol-Yong, H. Hye-Sim, L. Jin-Sook, The building energy efficiency rating evaluation of apartment depending on SC and window area ratio, The Korean Solar Energy Society 30 (5) (2010) 38-43.

[5] A. ALAnzi, D. Seo, M. Krati, Impact of building shape on thermal performance of office buildings in Kuwait, Energy Conversion and Management 50 (3) (2009) 822-828.

[6] Passive Solar House Design, CMHC (Canada Mortgage and Housing Corporation), Feb. 2012.

[7] W. Feist, Passive House Planning Package 2007-2nd Revised Edition of English PHPP 2007 User Guide, Passive House institute, Mar. 2010.

[8] K. Yeang, Designing with Nature: The Ecological Basis 
for Architectural Design, Mc Graw-Hill, USA, 1995.

[9] S. Lang, Energy and environmental of residential buildings in China, Energy and Buildings 36 (12) (2004) 1191-1196.

[10] C.F. Reinhart, J. Weinold, The daylighting dashboard-A simulation-based design analysis for daylit spaces, Building and Environment 46 (2) (2011) 386-396.

[11] C.F. Reinhart, D.A. Weissman, The daylit area-Correlating architectural student assessments with current and emerging daylight availability metrics, Building and Environment 50 (2012) 155-164.

[12] A. Nabil, J. Mardaljevic, Useful daylight illuminances: A replacement for daylight factors, Energy and Buildings 38 (7) (2006) 905-913.

[13] K. Dong-Hwan, Analysis of useful daylight illuminance (UDI) by dynamic daylight simulation using weather data, Journal of Architectural Institute of Korea 26 (6) (2010) 321-331.

[14] F. Chella, Compared numerical and reduced scale experimental analysis on light pipes performances, in: 5th International Conference on Sustainable Energy Technologies, USA, 2006.

[15] C.F. Reinhart, O. Walkenhorst, Validation of dynamic RADIANCE-based daylight simulations for a test office with external blinds, Building and Buildings 33 (7) (2001)
683-697.

[16] S.R. Chinnayeluka, Performance assessment of innovative framing systems through building information modeling based energy simulation, Master Thesis, Osmania University, 2011, pp. 32-71.

[17] A. Kwang-Ho, K. Hyung-Keun, C. Yong-Seok, A Study on energy conservation plan of eco-friendly school by energy plus, Journal of Architectural Institute of Korea 27 (12) (2011) 19-26.

[18] Department of energy, Energy Plus, http://apps1.eere.energy.gov/buildings/energyplus (accessed Jan. 1, 2013).

[19] Guidelines for Green Building Design for a Low-Carbon Green Growth, Incheon City, Apr. 2010.

[20] L. Jang-Bum, Study on the application methods of the various types of apartment buildings based on the sun shade layout and the possibility of the advanced application to PUD planning, Journal of Architectural Institute of Korea 27 (2011) 165-176.

[21] K. Moon-Il, A study on the application criteria of daylight prescription, Journal of Architectural Institute of Korea 25 (2009) 99-106.

[22] M. Moeck, Y.J. Yoon, Green building and potential electric light energy savigs, Journal of Architectural Engineering 10 (4) (2004) 143-159. 